\title{
Exploring the obesity epidemic
}

\author{
Carolyn M. Matthews, MD
}

$\mathrm{n}$ our lifetime we are experiencing never before seen rates of obesity, with a $68 \%$ rate of overweight in adults. In my field of gynecologic oncology, our surgical cases have become tremendously challenging due to the large size of our patients. When I was in residency training in the mid 1980s, it was rare to have a patient over $200 \mathrm{lb}$. Now it is uncommon to have a patient under $200 \mathrm{lb}$.

Our hospitals have had to make accommodations for the rising tide of obesity, increasing the sizes of beds, wheelchairs, operating instruments, and scales. I'll never forget the time when my brother came to Baylor for magnetic resonance imaging (MRI) as recently as 1998 and was turned away because he was over the weight limit of $375 \mathrm{lb}$. Now we have machines that can perform an MRI on patients up to $550 \mathrm{lb}$.

No one chooses to be obese. Science has shown that gluttony and sloth are not the major culprits. While some genes will predispose to obesity and insulin resistance, our genes wouldn't have changed enough in 20 years to account for the drastic change between 1990, when no state had a $20 \%$ obesity rate, and 2010, when all states had obesity rates of $\geq 20 \%$.

There has to be a reason why we've had such a drastic change in the human phenotype-the way we look-in the last 20 years. Our genes just don't evolve or change that quickly. If our genes haven't changed, what has?

Our environment. While multiple factors contribute to obesity, the major game-changers that have contributed to this perfect storm are foods that had not previously been consumed during human evolution: proteins from genetically modified (GM) organisms, high fructose corn syrup (HFCS), and everincreasing quantities of refined sugar and grains, as well as persistent organic pollutants.

GM foods, most commonly soy and corn, were introduced in the 1990s, just as the obesity epidemic was starting. Humans had never consumed GM foods, yet they are now rampant in our grocery stores and are typically found in processed foods and fast foods. In Morgan Spurlock's month-long experiment of eating only fast foods, he gained $25 \mathrm{lb}$ in 30 days!

Much of our immune system resides in our gut, and one important task is for our immune system to develop tolerance to the dietary nutrients that then become incorporated into our cells. It makes sense that if our immune systems had not encountered proteins from GM foods before, an inflammatory reaction could be generated. GM foods may be close to a wildtype food but have enough subtle differences that our immune systems react as if the molecules are a possible threat.

While numerous 90-day feeding studies of rats in well-controlled environments suggest safety and "substantial similarity" between regular foods and GM foods, no clearly reassuring long-term multigenerational studies have been conducted. A recent study from France looked at how feeding three different GM strains of corn affected young adult rats, comparing them to isogenic rats fed non-GM foods. The results are particularly intriguing given our worldwide obesity epidemic: the researchers found sex- and dose-dependent changes in numerous metabolic functions. Females fed MON 863 corn had up to $40 \%$ increases in serum triglycerides and glucose levels, a physiological state like metabolic syndrome. Hepatorenal effects, thought to be related to the pesticide residues produced as a result of the genetic modification, were prominent in all groups (1). Until there is long-term safety data on GM foods in laboratory animals, it would be prudent not to include these foods in our diet, and certainly Americans should have the option, like Europeans, of knowing whether the food they are eating contains molecules of GM food or not.

We've been evolving for millions of years, yet we've only had farming for 10,000 years, so we've had grains in our diet for the blink of an eye in evolutionary terms. Both grains and sugar are now readily available in massive quantities year round, and we are eating or drinking grains and sugar in unprecedented quantities. Medical anthropologists suggest that in the Paleolithic age, we consumed 20 teaspoons of sugar a year in the form of vegetables and fruits; now the average American consumes about 27 teaspoons a day. Refined sugars now comprise approximately $20 \%$ of our dietary caloric intake (2).

Since the industrial revolution, which enabled us to refine both grains and sugar, we have been eating huge quantities of

From the Office of Integrative Medicine, Baylor Charles A. Sammons Cancer Center at Dallas, and the Division of Gynecologic Oncology, Baylor University Medical Center at Dallas.

Corresponding author: Carolyn M. Matthews, MD, 3410 Worth Street, Suite 400, Dallas, Texas 75246 (e-mail: Carolyn.Matthews@BaylorHealth.edu). 
high-glycemic index carbohydrates, which are digested and absorbed quickly. It is commonplace and socially acceptable to sit down with a soda; most sodas have close to our Paleolithic annual intake of sugar in one fell swoop-oops, I meant swallow!

Not only is the quantity of sugar a problem, but much of it has been replaced by HFCS, which doesn't occur in nature. Fructose is found in some vegetables and fruits in small quantities, but we consume huge quantities with the most common form of HFCS, normally $55 \%$ fructose and $42 \%$ glucose (3).

A technique to industrially produce HFCS was developed in 1966 by a Japanese scientist, Dr. Y. Takasaki. It was introduced to the American market in 1975 when it was still fairly rare to see an obese person. The dramatic rise in obesity has paralleled the rise of HFCS in our diet (4). HFCS is metabolized in the liver in a way that promotes hepatic lipogenesis (4), contributing to fatty liver and metabolic syndrome. We are now consuming $63 \mathrm{lb}$ of HFCS per person in this country annually, often in baked goods but also in sodas and other foods. Why? It is inexpensive! Our tax dollars make corn inexpensive.

Also contributing to these environmental changes are the persistent organic pollutants that surround us - the billions of pounds of chemicals that have been poured into our environment, mostly in the last 100 years, in the form of industrial byproducts, pesticides, herbicides, and now pharmaceutical byproducts (oral contraceptives and hormone replacement therapy) that are contaminating our water supplies. We've never before in our evolution been exposed to chemicals in these amounts or these combinations. Many are known carcinogens and have been banned (like DDT, banned now in the United States but still used in many countries) but are persistent in nature. Many act as endocrine disruptors, interfering with our hormonal system, which is intimately involved in the way we burn and use energy.

While it is not clear precisely how the environmental contaminants interfere with our hormones, we do know through the work of Dr. Duk-Hee Lee and collaborators that there is a striking dose-response relation between blood levels of persistent organic pollutants and the prevalence of diabetes mellitus: individuals with the highest level of persistent organic pollutants have a 37-fold increased risk of diabetes compared to those in those lowest quartile (5). In fact, obesity doesn't even seem to be related to type 2 diabetes in individuals with low serum concentrations of persistent organic pollutants (6).

So what can we do ? Something has to change; this path of ever-increasing obesity with its associated diseases is not sustainable in our society. My recommendation is to vote with your fork and your wallet: if we don't buy it, food producers will adjust accordingly. Choose your foods with great discrimination. Lobby your representatives to encourage sustainable farming practices and end subsidies for corn and soy. Eliminate GM foods, limit your intake of refined grains and sugars, and avoid HFCS. Eat in the way we have evolved over the millennia—vegetables, fruits, nuts, seeds, berries, and pasture-raised or wild meats.

1. de Vendômois JS, Roullier F, Cellier D, Séralini GE. A comparison of the effects of three GM corn varieties on mammalian health. Int J Biol Sci 2009; 5(7):706-726.

2. Cordain L, Eaton SB, Sebastian A, Mann N, Lindeberg S, Watkins BA, O'Keefe JH, Brand-Miller J. Origins and evolution of the Western diet: health implications for the 21st century. Am J Clin Nutr 2005;81(2):341354.

3. Hanover LM, White JS. Manufacturing, composition, and applications of fructose. Am J Clin Nutr 1993;58(5 Suppl):724S-732S.

4. Bray GA, Nielsen SJ, Popkin BM. Consumption of high-fructose corn syrup in beverages may play a role in the epidemic of obesity. Am J Clin Nutr 2004;79(4):537-543.

5. Lee DH, Lee IK, Song K, Steffes M, Toscano W, Baker BA, Jacobs DR Jr. A strong dose-response relation between serum concentrations of persistent organic pollutants and diabetes: results from the National Health and Examination Survey 1999-2002. Diabetes Care 2006;29(7):1638-1644.

6. Lee DH. Persistent organic pollutants and obesity-related metabolic dysfunction: focusing on type 2 diabetes. Epidemiol Health 2012;34:e2012002. 